\title{
Nilai Budaya Manugal bagi Pembentukan Karakter dalam Melestarikan Kearifan Lokal Masyarakat Suku Dayak Ngaju di Kalimantan Tengah
}

\author{
Manugal Cultural Values for Character Building in Preserving Local Wisdom of the \\ Ngaju Dayak Tribe in Central Kalimantan
}

Timotius Dehen L. Djungan

Program Studi Magister Manajemen Fakultas Pascasarjana

Universitas Palangka Raya

\section{ARTICLE INFO}

Article history:

DOI:

$\underline{10.30595 / p s p f s . v 2 i .204}$

Submitted:

July 29, 2021

Accepted:

Sept 10, 2021

Published:

Nov 10, 2021

Keywords:

Manugal, Ngaju Dayak Tribe, Local Wisdom, Central

Kalimantan

\begin{abstract}
The traditional manugal culture (growing rice) is still carried out by the indigenous Ngaju tribe in Central Kalimantan. In manugal there is a division of labor between men, mothers and children. The manual farming method cannot be separated from the system of burning land which makes it unfriendly to the environment and is being abandoned by indigenous peoples. In fact, manugal can be used as an environmentally friendly way of farming by reusing land that has been burned, plowing the soil again and applying organic fertilizer, manure and chemical fertilizers. Apart from that, in human culture there are values that must be maintained because these values shape the character of children to be responsible and help others. These values include the value of handep hapakat (mutual cooperation), the value of patience, the spiritual value between nature, humans and God.
\end{abstract}

This work is licensed under a Creative Commons Attribution 4.0 International License.

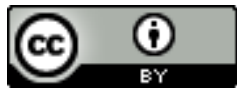

Corresponding Author:

Timotius Dehen L. Djungan

Program Studi Magister Manajemen Fakultas Pascasarjana

Universitas Palangka Raya

Email: timotiusdehenldjungan@mhs.it.upr.ac.id

\section{PENDAHULUAN}

Kemajuan teknologi bagaikan sebuah mata pisau dengan dua sisi tajam berlawanan yang membawa keuntungan dan kerugian disaat bersamaan. Teknologi merupakan bagian yang sangat penting dan tidak dapat dilepaskan dari kehidupan manusia, contohnya adalah dengan semakin maraknya penggunaan telepon genggam dalam setiap aktivitas pekerjaan manusia sehari-hari.

Dengan berbagai dalih serta alasan pekerjaan yang tidak dapat diganggu-gugat atau kesibukan lainnya, sebagian besar generasi muda saat ini banyak menghabiskan waktunya secara berlebihan dalam menggunakan telepon genggam. Akibat penggunaan telepon genggam secara berlebihan ini, banyak memunculkan bahkan menjadi alasan bagi anak-anak untuk tidak belajar bahkan sebagian kecil ada yang tidak mengetahui kearifan lokal daerahnya sendiri.

Sebagai sebuah suku yang ada di Kalimantan Tengah, suku dayak ngaju tentu saja memiliki sebuah kearifan lokal, kearifan lokal tersebut adalah manugal. Kearifan lokal merupakan bagian dari budaya suatu masyarakat yang tidak dapat dipisahkan dari masyarakat itu sendiri. Kearifan lokal diwariskan turun-temurun 
dari satu generasi ke generasi lainnya melalui cerita dari mulut ke mulut oleh orang tua, tetua keluarga kepada anak-anak atau cucu-cucunya. Manugal (bercocok tanam padi) merupakan salah satu kearifan lokal dalam bidang pertanian yang termasuk dalam pemanfaatan sumber daya alam. Kearifan lokal ini masih sangat tradisional dan berkaitan erat dengan sistem "membakar lahan" untuk membuka ladang. Sebagai kearifan lokal yang masih menggunakan sistem pertanian tradisional, kearifan lokal ini dianggap tidak ramah lingkungan dan membahayakan jiwa, jika lalai dalam melakukan pembakaran lahan bisa memakan korban jiwa dan menimbulkan kebakaran hutan.

Adanya pandangan sebagian masyarakat yang menganggap budaya manugal sebagai kearifan lokal sudah kuno, juga ada berbagai faktor seperti pemukiman penduduk sudah semakin padat, hutan-hutan sudah semakin menipis dan jika ketahuan membakar hutan akan ditangkap oleh polisi mengakibatkan kearifan lokal ini mulai ditinggalkan oleh masyarakat adat. Padahal, kearifan lokal seperti budaya manugal ini bisa saja dijadikan sebagai pemanfaatan sumber daya alam yang ramah lingkungan tanpa membakar lahan untuk menjadikan ladang, salah satunya adalah dengan kembali menggunakan lahan-lahan yang sudah pernah dibakar, menebang kembali pohon atau semak belukar yang tumbuh diatasnya, kembali melakukan pencangkulan pada tanahnya dan memberi pupuk organik pupuk kandang maupun pupuk kimia.

Berdasarkan permasalahan di atas, maka diangkatlah sebuah penelitian berjudul "Nilai Budaya Manugal Bagi Pembentukan Karakter Dalam Melestarikan Kearifan Lokal Masyarakat Suku Dayak Ngaju di Kalimantan Tengah". Berdasarkan uraian latar belakang diatas maka dapat dirumuskan pertanyaan penelitian sebagai berikut: (1) Apa saja nilai yang terkandung dalam tradisi budaya manugal suku Dayak Ngaju di Kalimantan Tengah, (2) Bagaimana peran budaya manugal dalam pembentukan dan pengembangan karakter dan (3) Bagaimana peran pemerintah daerah, tokoh-tokoh adat dan pihak-pihak lain seperti guru, dosen, atau peneliti yang berkutat dengan lingkungan akademik dalam melestarikan tradisi budaya manugal sebagai budaya daerah Dayak Ngaju. Sedangkan tujuan yang ingin dicapai dalam penelitian ini adalah: (1) Menganalisis nilai yang terkandung dalam tradisi budaya manugal suku Dayak Ngaju di Kalimantan Tengah, (2) Menganalisis pengaruh budaya manugal dalam pembentukan dan pengembangan karakter dan (3) Menganalisis peran pemerintah daerah, tokoh-tokoh adat dan pihak-pihak lain seperti guru, dosen, atau peneliti dalam melestarikan tradisi budaya manugal sebagai budaya daerah dayak ngaju.

Manfaat dari penelitian diharapkan dapat memberi kontribusi sebagai berikut: (1) secara teoritis diharapkan dapat menjadi bahan referensi tertulis akademis tentang budaya manugal untuk pembentukan karakter dalam melestarikan budaya suku dayak ngaju; (2) secara praktis diharapkan dapat menjadi bahan evaluasi bagi pemerintah daerah, tokoh-tokoh adat dan pihak-pihak lain seperti guru, dosen, atau peneliti yang berkutat dengan lingkungan akademis untuk melestarikan kearifan lokal ini.

\section{METODE PENELITIAN}

\section{Jenis dan Sumber Data}

Penelitian ini adalah penelitian kualitatif dengan menggunakan metode pengumpulan data sekunder: studi pustaka dengan teknik dokumentasi. Studi pustaka dengan teknik dokumentasi adalah dengan mengumpulkan data melalui referensi tertulis seperti buku, artikel, jurnal yang relevan dengan masalah penelitian. Data yang diperoleh nantinya akan diolah sehingga menjadi informasi baru yang bermanfaat bagi pembacanya.

\section{HASIL DAN PEMBAHASAN}

Penelitian ini dilakukan dengan menganalisis permasalahan yang telah dirumuskan dengan mengikuti ranah kognitif yang bersifat mengidentifikasi, mencari, membangun, menjelaskan, dan menganalisis dengan memeriksa suatu fenomena yang diteliti secara komprehensif dan dapat mendeskripsikan apa yang terjadi (what), mengapa itu terjadi (why) dan bagaimana hal tersebut terjadi (how).

Menurut tetek tatum (ratapan tangis) leluhur suku dayak ngaju merupakan ciptaan langsung Ranying Hatalla Langit yang bertugas menjaga bumi dan isinya agar tidak rusak dan diturunkan dari langit di empat tempat berturut-turut, menggunakan Palangka Bulau (suci atau bersih) yang berfungsi sebagai tandu yang suci, gandar suci dari emas (Ancak atau Kalangkang).

Salah satu kearifan lokal yang dimiliki oleh suku Dayak Ngaju di Kalimantan Tengah adalah budaya manugal. Manugal adalah kegiatan menanam padi secara tradisional yang dilakukan oleh masyarakat adat sekali dalam setahun, dan untuk beberapa daerah waktu pelaksanaan manugal tidaklah sama. Dibeberapa daerah ada yang melakukannya pada bulan Agustus, sedangkan dibeberapa daerah lainnya ada yang pada bulan September ataupun Oktober.

Dalam kegiatan manugal terdapat pembagian tugas antara kaum laki-laki dan kaum ibu-ibu serta anakanak. Kaum laki-laki biasanya akan bertugas menjadi panugal (bertugas membuat lubang di tanah), sedangkan kaum ibu-ibu dan anak-anak bertugas menjadi penabur bibit padi. Seringkali pada beberapa daerah yang masyarakat-Nya masih memeluk agama helu yakni agama Kaharingan. Sebelum melakukan kegiatan manugal seringkali para pemilik ladang atau pemilik kegiatan manugal mengadakan kenduri dan doa syukur kepada 
pencipta agar kegiatan manugal berlangsung dengan baik dan dijauhkan dari segala marabahaya yang kerapkali mengintai. Setelah kegiatan doa bersama ini selesai dilakukan oleh masyarakat adat, barulah kemudian mereka melakukan kegiatan manugal ini secara bersama-sama di ladang. Ciri khas dari budaya manugal adalah proses para panugal yang mulai mengambil posisi untuk melubangi tanah dengan menghujamkan kayu panjang yang ujungnya dibuat seperti mata tombak sehingga memudahkan panugal untuk membuat lubang di tanah, sedangkan kaum ibu-ibu serta anak-anak akan menaburkan bibit padi ke dalam lubang yang sudah dibuat oleh panugal. Lubang yang sudah dibuat dan ditaburkan bibit padi ini tidak ditutup dengan rapat dengan tanah agar bibit dapat menembus tanah dan hidup. Kegiatan ini dilakukan secara terus-menerus sampai tanah selesai di lubangi dan bibit padi semuanya habis ditaburkan, setelah itu kegiatan manugal dapat dikatakan selesai.

Setelah proses manugal selesai dikerjakan, maka si pemilik ladang atau orang yang mengadakan kegiatan manugal ini akan mencatat nama-nama masyarakat adat atau orang-orang yang sudah bersedia membantunya manugal, disini juga pemilik kegiatan langsung mengundang orang-orang yang sudah membantunya dalam melaksanakan kegiatan manugal untuk dapat hadir dan ikut makan bersama di rumah orang tersebut. Tujuan pemilik ladang yang mencatat nama-nama orang yang membantunya manugal adalah agar dapat melakukan handep hapakat (gotong-royong) di kemudian hari apabila orang yang sudah membantunya ini ingin membuka ladang atau melaksanakan kegiatan manugal yang memerlukan banyak orang.

Penelitian yang dilakukan oleh Suryanti, Mz, I. and Rahmah, S. (1941) mengatakan bahwa aktivitas budaya handep merupakan nilai kearifan lokal suku Dayak Kalimantan Tengah yang terwujud pada praktek kerjasama dalam beberapa bentuk pekerjaan seperti, membuka hutan sebagai lahan pertanian, menanam bibit padi sampai pada masa panen, melaksanakan upacara adat pernikahan, melaksanakan kerjasama pendirian rumah, dan melaksanakan ritual kematian, semua aktivitas tersebut dilakukan dalam bentuk gotong-royong membangun kebersamaan dan saling bahu membahu meringankan beban pekerjaan masyarakat satu dengan yang lainnya tanpa memandang status agama dan sosial. Kegiatan sosial tersebut dilakukan berpola pada adat istiadat masyarakat sebagai sebuah kekayaan kearifan lokal budaya yang kemudian disebut sebagai budaya handep.

Penelitian yang dilakukan oleh Hadiwijoyo, E., Saharjo, B. H. and Putra, I. (2017) yang berjudul "Kearifan Lokal Masyarakat Dayak Ngaju Di Kalimantan Tengah Dalam Melakukan Penyiapan Lahan Dengan Pembakaran" dengan kesimpulan bahwa pengelolaan lahan gambut yang dilakukan oleh masyarakat adat Dayak Ngaju masih dilakukan secara tradisional dengan menggunakan sistem handel. Penyiapan lahan dengan menggunakan api masih tetap dilakukan masyarakat karena tidak adanya teknologi lain yang lebih baik. Pembakaran lahan dilakukan oleh masyarakat untuk membuat tanah lebih subur agar mereka memperoleh hasil padi yang lebih banyak. Saat ini masyarakat adat Dayak Ngaju sering merasa kesulitan dalam menentukan waktu pembakaran yang tepat akibat terjadinya perubahan iklim.

Penelitian yang dilakukan oleh Efendi, M., Sahrul, M. and Salma, S. (2020) dengan judul "Nilai Kearifan Lokal Tradisi Manugal Masyarakat Dayak Meratus Kalimantan Selatan Pada Materi Geografi Bidang Lingkungan Hidup (Kajian Etnografi)", dengan kesimpulan bahwa masyarakat adat secara tradisi terus berpegang pada nilai-nilai lokal yang diyakini kebenaran dan kesakralannya serta menjadi pegangan hidup anggotanya yang diwariskan secara turun temurun. Nilai-nilai tersebut saling berkaitan dalam sebuah sistem.

Endang Hartati (2018), menyatakan bahwa Budaya 'Handep' bukan hanya menjadi tradisi biasa dalam masyarakat tetapi juga menjadi konsep penting dalam kepribadian masyarakat Dayak Ngaju di Kalimantan Tengah, dimana mereka merasa ada yang kurang bahkan ada perasaan bersalah apabila tidak ikut ambil bagian dalam 'handep' dan membayar 'handep'. Ini menandakan bahwa 'handep' bukan hanya konsep yang umum dalam masyarakat tetapi juga menjadi konsep yang melekat dalam kepribadian individu dalam masyarakat.

Manugal merupakan salah satu kearifan lokal terutama dalam pemanfaatan sumber daya alam yakni bidang pertanian. Manugal (bercocok tanam padi) merupakan sistem pertanian tradisional yang diwariskan oleh leluhur dan tetap berjalan sampai sekarang ini. Kearifan lokal ini masih menggunakan sistem "membakar lahan" untuk membuka ladang, oleh karena itu kearifan lokal ini dianggap tidak ramah lingkungan dan jika lalai dalam melakukan pembakaran lahan bisa menimbulkan kebakaran hutan. Hal ini mengakibatkan kearifan lokal ini mulai ditinggalkan oleh masyarakat adat, karena berbagai faktor seperti pemukiman penduduk sudah semakin padat, hutan-hutan sudah semakin menipis dan jika ketahuan membakar hutan akan ditangkap oleh polisi.

Adanya anggapan bahwa kearifan lokal ini tidak begitu signifikan mendukung perekonomian masyarakat memicu sebagian kecil masyarakat tidak memperkenalkan adanya kearifan lokal ini kepada anak-anak. Perkembangan zaman yang semakin maju semakin membuat kearifan lokal terkikis karena sebagian besar anakanak generasi muda saat ini tidak lagi berkumpul untuk memainkan sebuah permainan karena dikalahkan oleh game-game online yang ada di telepon genggam masing-masing. Oleh karena itu, diperlukan campur tangan dari pemerintah daerah, tokoh-tokoh adat dan pihak-pihak lain seperti guru, dosen, atau peneliti yang berkutat dengan lingkungan akademis untuk melestarikan kearifan lokal ini.

(Hartati, 2018, p. 3) dalam judulnya "Penerapan Konsep Kearifan Lokal Masyarakat Suku Dayak Ngaju (Handep) Dalam Pembelajaran Sejarah Di SMA Negeri 4 Palangka Raya", mengatakan Dalam Pedoman Khusus Sejarah Lokal Kota Palangka Raya menyebutkan, setidaknya ada tiga langkah yang harus dilakukan 
untuk mewujudkan hal tersebut, yaitu 1) pemahaman untuk menimbulkan kesadaran, (2) perencanaan secara kolektif, (3) pembangkitan kreatifitas kebudayaan.

Dalam kearifan lokal budaya manugal suku Dayak Ngaju di Kalimantan Tengah terdapat nilai-nilai sosial budaya yang terkandung antara lain: nilai handep hapakat (gotong-royong), nilai kesabaran, nilai spiritual antara alam, manusia dan Tuhan.

Nilai handep hapakat (gotong-royong) adalah bentuk balas budi dari pemilik kegiatan manugal sebelumnya kepada orang-orang, masyarakat, tetangga yang sudah membantunya secara sukarela. Nilai handep hapakat, apabila diamati secara keseluruhan terutama pada keseluruhan kegiatan manugal akan didapati pesan untuk menjaga dan melestarikan adat-istiadat suku Dayak Ngaju di Kalimantan Tengah. Sistem kekeluargaan dengan nilai handep hapakat (gotong-royong) bagi masyarakat adat di pedalaman begitu kuat dan kental. Dengan menghubungkan nilai sejarahnya ini maka setiap generasi suku Dayak Ngaju di Kalimantan Tengah, akan mampu mengenal jati diri asal usulnya, nilai sejarah pada tradisi budaya manugal ini selaras dengan semboyan Presiden Soekarno yang dikenal dengan nama "jas merah". Pada semboyan yang diucapkan Presiden Soekarno inilah nilai handep hapakat (gotong-royong) pada kearifan lokal budaya manugal mengajarkan kepada generasi muda bahwa manusia sebagai makhluk sosial tidak dapat lepas dari bantuan orang lain, saat ada yang sakit maka yang sigap membantu adalah orang terdekat yakni tetangga. Nilai handep hapakat (gotongroyong) ini juga mengajarkan kepada manusia agar saling menolong dan bertanggung-jawab.

Nilai kesabaran, pada kegiatan manugal, masyarakat adat atau pemilik yang memiliki kegiatan manugal tidak dapat memastikan panen berhasil. Mereka hanya dapat berharap hasil panen tidak mengecewakan, kegiatan manugal adalah kegiatan tradisional dimana semua prosesnya adalah manual dan kegiatan ini cukup memakan biaya dan waktu dikarenakan pemilik kegiatan karena meminta bantuan orang lain untuk membantunya haruslah menyediakan makanan dan minuman. Nilai kesabaran ini mengajarkan bahwa setiap kesuksesan yang diraih tidak luput dari sebuah proses perjuangan yang membentuknya sehingga menjadi berkarakter. Proses merupakan rangkaian hukum alam yang memerlukan waktu tidak sedikit dalam kehidupan. Dari kegiatan manugal ini dapat ditarik kesimpulan bahwa untuk mencapai keberhasilan ada harga yang harus dibayar dengan keringat dan waktu.

Nilai spiritual antara alam, manusia dan Tuhan, alam tidak dapat dipisahkan hubungannya dalam kehidupan manusia karena manusia tidak bisa hidup tanpa ada alam sedangkan alam bisa tanpa manusia. Nilai hubungan manusia dan Tuhan di lihat dari unsur campur tangan dari pencipta kepada manusia, tanpa ada unsur campur tangan pencipta melewati bantuan alam kepada manusia maka apapun pekerjaan yang dilakukan oleh manusia ini tidak akan pernah berhasil. Alam adalah bukti kekuasaan pencipta karena itulah manusia harus belajar dan menjalin komunikasi yang kuat terhadap pencipta dengan tidak melebihi batasnya sebagai makhluk ciptaan.

\section{KESIMPULAN}

Manugal sebagai kearifan lokal suku Dayak Ngaju di Kalimantan Tengah harus dipertahankan keberadaannya karena di dalam manugal banyak nilai-nilai dalam membentuk karakter anak menjadi bertanggungjawab dan membantu sesamanya. Nilai-nilai tersebut antara lain adalah nilai handep hapakat (gotong-royong), nilai kesabaran, nilai spiritual antara alam, manusia dan Tuhan.

\section{UCAPAN TERIMA KASIH}

Terimakasih sebesar-besarnya kepada masyarakat suku Dayak Ngaju di Desa Mungku Baru, Kecamatan Rakumpit, Kota Palangka Raya, Kalimantan Tengah.

\section{DAFTAR PUSTAKA}

Akbar, A. (2011) 'Studi Kearifan Lokal Penggunaan Api Persiapan Lahan: Studi Kasus di Hutan Mawas, Kalimantan Tengah', Jurnal Penelitian Sosial dan Ekonomi Kehutanan, 8(3), pp. 211-230. doi: 10.20886/jsek.2011.8.3.211-230.

Budiwibowo, S. (2016) 'Membangun Pendidikan Karakter Generasi Muda Melalui Budaya Kearifan Lokal Di Era Global', Premiere Educandum : Jurnal Pendidikan Dasar dan Pembelajaran, 3(01), pp. 39-49. doi: 10.25273/pe.v3i01.57.

Efendi, M., Sahrul, M. and Salma, S. (2020) 'Nilai Kearifan Lokal Tradisi Manugal Masyarakat Dayak Meratus Kalimantan Selatan Pada Materi Geografi Bidang Lingkungan Hidup (Kajian Etnografi)', PADARINGAN (Jurnal Pendidikan Sosiologi Antropologi), 2(2), p. 260 . doi: 10.20527/padaringan.v2i2.2158.

Fitria (2013) ‘済無No Title No Title’, Journal of Chemical Information and Modeling, 53(9), pp. 1689-1699.

Hadiwijoyo, E., Saharjo, B. H. and Putra, I. (2017) 'Kearifan Lokal Masyarakat Dayak Ngaju Di Kalimantan 
Tengah Dalam Melakukan Penyiapan Lahan Dengan Pembakaran Local Wisdom of Dayak Ngaju in Central Kalimantan on Land Preparation By Using Fire', Jurnal Silvikultur Tropika, 8(1), pp. 1-8.

Hartati, E. (2018) 'Application of The Concept of The Local Future of The Dayak Ngaju Community (Handep) in History Learning in SMA 4 Palangka Raya’, 6(1), pp. 1-7.

Heriansyah, M. (2017) 'Inventori Kepribadian Ideal Budaya Dayak Ngaju dalam Layanan Bimbingan dan Konseling', Jurnal Fokus Konseling, 3(2), p. 175. doi: 10.26638/jfk.318.2099.

Indomedia Australia. (2018, 21 September). "Tradisi Manugal Dayak Ngaju di Pentas Festival Brisbane", diakses 13 Juni 2021 dari https://indomedia.com.au/tradisi-manugal-dayak-ngaju-di-pentas-festivalbrisbane/

Lokal, K., Dayak, S. and Dunia, U. (no date) Pu Kung.

Meratus, O. B. (2011) 'Dayak Kalimantan', 8(1), pp. 1-5.

Riwut, T. and Mantikei, S. (2012) 'Maneser Panatau Tatu Hiang, Menyelami Kekayaan Leluhur’, pp. 1-582.

Suryanti, Mz, I. and Rahmah, S. (1941) 'RIHLAH Jurnal Sejarah dan Kebudayaan', Jurnal Rihlah, 8(2).

Zainuddin Hasan, 2012, Manugal Cara Tani Dayak di Pedalaman Kalimantan, Jakarta: Kompas online. 